\title{
MÉXICO-ESTADOS UNIDOS: ¿ADIÓS AL MITO?
}

Ana Paula Ordorica*

La monarquía absoluta, la dictadura militar, las bases orgánicas, la agregación a los Estados Unidos, el comunismo, la preponderancia de la raza indígena: todos estos extravios tienen sus apóstoles, sus escritores, sus conspiradores; mientras que el gobierno sin plan, sin apoyo político, sin fuerza, se reduce a conservar el statu quo y a vivir de la inercia general.

Mariano Otero al doctor Mora ${ }^{1}$

La geografía nos ha colocado en una posición que no permite eludir el debate. Hoy, más que nunca, la relación de México con Estados Unidos nos lleva a formularnos preguntas clave: ¿De dónde somos? ¿De Norteamérica o de América Latina? Siendo parte de ambos espacios geográficos, económicos y culturales, ¿cómo nos integramos constructivamente con ambos? En el intento de responder lo anterior se halla una tradición sobre lo que es la relación bilateral con la potencia vecina. Esta tradición está marcada por miedos y recelos. También por admiración y veneración. Por mitos. Un gran paquete envuelto con la idea de Estados Unidos

* Analista internacional. Agradezco a la Dra. Soledad Loaeza y al Profesor Peter Ward los comentarios al presente ensayo así como la hospitalidad de éste último en mi estancia en la Universidad de Texas en Austin.

${ }^{1}$ Citado en David Brading, Los orígenes del nacionalismo mexicano, 1973, México, Era, p. 96. 
como la fuerza extranjera que busca influir en nosotros y amenazar nuestro tesoro más valioso: nuestra identidad nacional.

Estados Unidos es visto como el gigante Goliat con el cual, nosotros, pequeño David -ipobres de nosotros!- estamos forzados a 'lidiar' para defender nuestra preciada e intocable identidad. El tremendísimo otro: ese es Estados Unidos. Mito de mitos en la historia de México.

Un mito se define como una historia que se crea con el propósito de explicar la manera como funciona algo y que, a base de repetición, llega a formar parte de las tradiciones de una cultura. En sus estudios sobre mitos, Claude Levi-Strauss ${ }^{2}$ los define como una herramienta que sirve para pensar, para clarificar y orientar la realidad. Un mito no es un dato sustentado por evidencias contundentes, comprobables, científicas, si se quiere, sino por la tradición que se crea con base en su repetición. Los mitos en las relaciones México-Estados Unidos son historias que nos sirven para explicar la compleja relación entre ambos países, que se han perpetuado hasta conformar parte de nuestras tradiciones. $^{3}$

Identificar y entender los mitos tiene un doble propósito. Primero, nos permite conocer de dónde surgen y cómo es que se establecen en el devenir histórico: por qué se aceptan, se alimentan y perduran. Segundo, nos permite valorar si queremos seguir alimentándolos: adoptarlos con más vigor, abrazarlos con mayor firmeza, o disiparlos y desterrarlos. Nos permite elegir entre decir o no adiós al mito.

El presente ensayo tiene como propósito identificar el que, a mi parecer, es el mayor mito en la relación bilateral México-Estados Unidos: la integración como sacrificio de nuestra identidad nacional. Es un mito que ha perdurado a lo largo de nuestra historia compartida

${ }^{2}$ Claude Levi-Strauss, The Raw and the Cooked, 1970, Nueva York, Harper and Row.

${ }^{3}$ Eric Hobsbawm menciona precisamente la necesidad de la historia y los historiadores de recurrir a la creación de tradiciones como legitimadores de las acciones políticas y como herramienta para cohesionar a las sociedades. (Eric Hobsbawm y Terrence Ranger, eds., The Invention of Tradition, 1983, Cambridge University Press.) Como se verá a lo largo del presente ensayo, el miedo, la admiración y el recelo de México hacia lo norteamericano han sido sentimientos que en cierta medida han cohesionado a los mexicanos como sociedad. 
y que no está presente sólo de nuestro lado de la frontera. Paradójicamente, en Estados Unidos son cada vez más las voces que advierten sobre los riesgos de la integración con México. Así, y en el marco de un acercamiento económico, político y social cada vez más dinámico, se invita a definir, clara y contundentemente, si queremos o no decir adiós al mito.

La idea que persiste, el mito, es que aun cuando el destino tiene reservado para México el progreso, el desarrollo y la modernidad, la vecindad con Estados Unidos -símbolo de todo lo anterior- no ha permitido nuestro florecimiento como país y cualquier acercamiento que tengamos con esta nación avasalladora, con quien no tenemos nada en común fuera de la cercanía geográfica, significa necesariamente ceder parte de nuestro tesoro más valioso: nuestra identidad nacional.

La pregunta pertinente a responder es si el mito se sostiene hoy; quizás en un momento en nuestra historia se justificaba por la manera en cómo surgió la nación que hoy es México - por la invasión temprana, por la mutilación del país, por la serie de conspiraciones que hacían el intento de desarrollarnos una empresa más difícil, por los constantes abusos y amenazas-. ¿Son nuestros resentimientos, prejuicios y estereotipos, presentes tanto en México como en Estados Unidos, tan fuertes, están tan enraizados, que es imposible revisarlos para saber si hoy preferimos decir adiós al mito? ¿Cuál es la necesidad de seguir alimentándolo?

Contestar lo anterior nos permite saber si el mito ha funcionado como freno a la capacidad del país para definir su situación con el mundo y sobre todo con los Estados Unidos. A la vez, es una invitación a construir una relación distinta con nosotros mismos y con el mundo en el futuro. Es el intento realista del adiós al mito.

\section{Nosotros y el otro: odio y veneración}

La identidad mexicana está compuesta por dos ingredientes: la cultura y la ideología política; está construida sobre las bases de un lenguaje, 
de costumbres, imágenes, valores y símbolos, y de la experiencia histórica. ${ }^{4}$ Eso es lo que compone el nosotros mexicano.

¿Y quién es ese otro, el norteamericano? El profesor de Harvard, Stanley Hoffmann, encuentra que los componentes de la identidad norteamericana son dos: la diversidad étnica y el credo ideológico, basado en los principios liberales y democráticos. ${ }^{5}$ Por su parte, Samuel Huntington traza las bases de la sociedad anglosajona en los siglos XVII y XVIII. Entonces la identidad nacional se definía en términos de raza, etnia, cultura y religión, componentes heredados de Gran Bretaña. Para fines del siglo XIX, el componente étnico se expandió para incluir a los inmigrantes alemanes, irlandeses y escandinavos que llegaron en gran número a Estados Unidos.

Posteriormente, con las olas migratorias provenientes del este de Europa tras el fin de la Segunda guerra mundial, y con su asimilación a la sociedad norteamericana, el componente étnico, al hallarse tan expuesto, se vio diluido como definitorio de la identidad nacional. La raza también dejó de ser parte de la identidad norteamericana a raíz de los movimientos en favor de los derechos civiles de los años sesenta. Así, a partir de los años setenta, la identidad estadounidense se ha definido más por el componente cultural y el ideológico. ${ }^{6}$ Desde entonces, las ideas y las instituciones que conforman la ideología liberal-democrática han sido el centro sobre el cual ha girado la identidad cultural de nuestro vecino.

Ese nosotros y el otro, el intento de construir nuestra identidad y de encontrar la identidad de 'el otro', ha llevado al país por grandes andanzas: la Independencia (1810), cuando 'el otro' era España, el intento de reconquista de España (1829), la pérdida de Texas (1836), la guerra con Estados Unidos (1848), el intento Imperial de Santa Anna

${ }^{4}$ Soledad Loaeza, "The Changing Face of Mexican Nationalism", en M. Delal Baer y Sydney Weintraub, eds., 1994, The NAFTA Debate, Boulder, Colorado, p. 148.

${ }^{5}$ Stanley Hoffmann, "More Perfect Union: Nation and Nationalism in America", Harvard International Review (Invierno 1997/1998), citado en Samuel Huntington, Who are we?, 2004, NY, Simon \& Schuster Paperbacks, p. 37.

${ }^{6}$ Huntington, op. cit., p. 37-8. 
(1850-54), la Revolución de Ayutla de 1854, la Constitución Liberal de 1857, el conflicto con Francia (1861-67), el intento monárquico de Maximiliano de Habsburgo (1864), el triunfo liberal (1867), la República Restaurada (1867-76), la dictadura de Díaz (1884-1910), la Revolución Mexicana (1910-20), la Revolución Institucionalizada (1929-1988) y actualmente el ejercicio de la democracia.

En todos estos episodios está la presencia, de una u otra forma, 'del otro'. Venerados y repudiados, los Estados Unidos simbolizan la ambivalencia: la promesa de oportunidades de desarrollo, pero también el miedo. La tentación a imitarlos y a la vez la tendencia a odiarlos. La relación que diluye en ocasiones los sentimientos de patriotismo -que implican amor por la República, por las instituciones políticas y por la vida que promueve la libertad-abriendo paso al ferviente nacionalismo que invoca la defensa a ultranza de la homogeneidad de los mexicanos; de nuestra cultura, idioma y raza. ${ }^{7}$ En esa dicotomía se ha movido históricamente la relación de México con Estados Unidos.

Siendo los ideales de libertad y democracia el centro de la identidad de nuestro vecino, ideales por los cuales en México hemos luchado desde la Guerra de Independencia, ¿de dónde y por qué surge este desprecio tan generalizado por lo anglosajón? Sí; sabemos que existen grandes diferencias culturales, religiosas, de idioma y sociales entre México y Estados Unidos. Véase el siguiente párrafo extraído de un libro escrito por un norteamericano en 1914:

${ }^{7}$ Para una definición profunda sobre patriotismo y nacionalismo ver Maurizio Viroli, For Love of Country. An Essay on Patriotism and Nationalism, 1995, Oxford University Press. Aquí, Viroli abre su libro con una cita muy pertinente de John Stuart Mill: “Apenas es necesario decir que por [principio de nacionalismo] no queremos referirnos a una antipatía sin sentido por los extranjeros; o el abrigar absurdas peculiaridades simplemente porque son nacionales; o el rechazo de adoptar aquello que ha sido probado positivo por otros países. En todos estos sentidos, las naciones que han tenido el más fuerte espíritu nacional han sido los menos nacionalistas. Nos referimos al principio de simpatía, no de hostilidad; de unión, no de separación. Nos referimos a un sentimiento de interés común entre aquellos que viven bajo el mismo gobierno y habitan dentro de las mismas fronteras naturales o históricas." John Stuart Mill, A System of Logic, VI. 10. 5. 
Los mexicanos se deleitan en las metáforas. Los americanos creemos en llegar directo al punto. Los mexicanos se deleitan en componer oraciones elegantes. Los americanos somos francos y hasta abruptos. En suma, los americanos somos diferentes en todos los aspectos a los mexicanos y por eso nos odian. Somos diferentes en todos sentidos a los mexicanos y por eso los odiamos. ${ }^{8}$

En un párrafo queda plasmado el estereotipo de la relación MéxicoEstados Unidos que en un siglo ha cambiado poco. Pero, ¿de dónde surgen estos rencores, recelos y resentimientos? ¿De dónde surge el mito?

Los primeros en hacer parte de su ideología la hostilidad hacia Estados Unidos fueron los conservadores del siglo XIX, encabezados por Lucas Alamán. Como buenos conservadores, éstos exaltaban las virtudes de la religión católica. La religión protestante, la principal en el país vecino, representaba para ellos la encarnación de la crueldad, el desorden, la sedición, la sangre y la muerte. ${ }^{9}$

Si tomamos en cuenta que el nacionalismo de México proviene de tres elementos, a saber, territorio, soberanía y autonomía, los cuales ya para los años de Alamán se habían visto amenazados todos de alguna u otra manera por los Estados Unidos, no es de sorprender la naturalidad con que los sentimientos antiamericanos florecieron. Sin embargo, si miramos años atrás en la historia, encontramos que la base de la resistencia conservadora a todo lo que se percibiera como anglosajón provenía de lo que David Brading ha llamado ‘el patriotismo criollo’: el antecedente del nacionalismo mexicano.

El patriotismo criollo llevó a la exaltación de nuestras raíces indígenas. Los conservadores del siglo XIX se sintieron naturalmente atraídos por una visión que promovía la idea de un México pre-colonial

${ }^{8}$ Marshall Everett (pseudónimo), Exciting Experiences in our War with Mexico, 1914, Chicago, The Bible House, p. 211. Colección Benson de América Latina, Biblioteca de la Universidad de Texas en Austin.

${ }^{9}$ Charles A. Hale, Mexican Liberalism in the Age of Mora, 1821-53, citado en Alan Knight, U.S.-Mexican relations 1910-1940, 1987, University of California in San Diego, p. 41. 
auténticamente católico. La llegada de los españoles es, en términos históricos, reducida. No fueron ellos quienes trajeron la civilización y la religión católica al Nuevo Mundo, aunque sí los que la asentaron. La justificación de la colonización para evangelizar a los pueblos indígenas de la Nueva España es devastada por el patriotismo criollo.

El patriotismo católico de Francisco Xavier Clavijero y las evocaciones metafóricas del historiador italiano Lorenzo Boturini sirvieron como antecedentes para las pruebas presentadas por Fray Servando Teresa de Mier: Quetzalcóatl no fue otro que Santo Tomás, el apóstol del Nuevo Mundo. La aparición de la Virgen de Guadalupe en 1531 en el Tepeyac no sólo era la prueba divina de la superioridad de México sobre cualquier nación, sino la prueba de que aun antes de la Conquista, los indios ya adoraban a María en este Valle. “¿No es éste el pueblo escogido, la nación privilegiada y la tierna prole de María señalada en todo el mundo con la insignia gloriosa de su especial protección?", ${ }^{10}$ preguntó Mier a la congregación en el famoso sermón del Tepeyac, el 12 de diciembre de 1794.

Casi un siglo después, los conservadores, encabezados por Lucas Alamán, retomarían algunas de las nociones fundadoras del patriotismo criollo: el guadalupanismo, el enaltecimiento del pasado indígena y la exaltación de Quetzalcóatl. ${ }^{11}$ A ello le agregarían la admiración hacia Hernán Cortés, hacia los jesuitas y a la herencia colonial vista como un período glorioso y de estabilidad para el país. En el marco de los acontecimientos nacionales e internacionales de mediados del siglo XIX, Alamán y los conservadores también sumaron otro elemento al nacionalismo: el odio hacia Estados Unidos, visto primero sólo con sospechas, las cuales se confirmaron y lo convirtieron en el temido ogro devorador tras la guerra de 1846-48.

Desde entonces, la tradición ha sido ver en Estados Unidos al descorazonado conspirador que abusó de la joven nación al sur. México como la víctima; Estados Unidos como el cíclope astuto y sanguinario.

${ }^{10}$ David Brading, op. cit., p. 48.

${ }^{11}$ Héctor Aguilar Camín, “La invención de México”, en Nexos, n 187, julio 1993, p. 51. 
Pero al mismo tiempo, Alamán y los conservadores convivían con el grupo de liberales que pugnaban por modernizar al país mediante la imitación y adopción de las instituciones y los ideales estadounidenses. ¡Qué mejor prueba de la validez de admirar a la nación vecina que tomar como base su logro de librarse del yugo de una potencia europea! El odiado y temido otro era a la vez venerado por los liberales mexicanos.

La joven nación mexicana se debatía entonces entre la disyuntiva de seguir siendo como ya era por herencia del pasado colonial (tesis conservadora), o llegar a ser, por imitación, como Estados Unidos (tesis liberal). ${ }^{12}$ Esto llevó, entre otras cosas, al conocido conflicto entre liberales y conservadores. A diferencia de los conservadores, la pérdida de la mitad del territorio a manos del gigante estadounidense no hizo más que demostrar a los liberales, de nuevo, la superioridad a la cual se podría arribar tan sólo con adoptar el republicanismo federal democrático. La esperanza de modernizar al país radicaba en imitar sus instituciones; lo demás: el desarrollo, la democracia, la justicia y la libertad, se darían por añadidura.

Así fue justificada y explicada la alianza con la potencia imperial que acababa de cercenar a la indefensa y joven nación que era México. Esta 'alianza' entre los liberales con los Estados Unidos fue determinante en el triunfo de dicha corriente sobre el intento monárquico de Maximiliano de Habsburgo. Los conservadores, aun cuando acusaban de 'traición' a los liberales por recurrir al extranjero por ayuda, habían también acudido a una potencia extranjera en su defensa: Francia. No obstante, por una serie de razones dentro de las cuales no se puede ignorar el momento político por el que atravesaba Francia, de guerras coloniales y conflictos fronterizos, los conservadores perdieron la guerra civil que marcó el turbulento siglo XIX mexicano. El triunfo liberal (apoyado por los Estados Unidos) sobre el intento monárquico (apoyado por Francia) condujo al matrimonio, en México, de liberalismo y nacionalismo.

${ }^{12}$ Edmundo O' Gorman, México: el trauma de su historia, CONACULTA, 1997, p. 31. 


\section{El mito se robustece}

El nacionalismo político que enaltecía a la nación mexicana fue la bandera tanto de liberales como de conservadores desde la independencia hasta la pérdida de la guerra con Estados Unidos. Entre sus diferencias, ambos 'campos' compartían uno de los pilares del patriotismo: la devoción por la Virgen de Guadalupe. No obstante, a partir de la visión divergente en cuanto a quién representaba el modelo a seguir - la colonia o el vecino del norte- el conflicto marcó al país. El pleito era por conquistar 'nuestra nacionalidad' $y$, como se anota líneas arriba, una serie de factores inclinaron la balanza del triunfo en favor de los liberales. Su promesa, a partir de 1867, fue la de lograr la modernización de la nación mexicana con base en el republicanismo copiado de los Estados Unidos.

Pero la promesa fue incumplida. La debilidad intelectual del liberalismo mexicano, que no acabó por definir claramente su postura frente al pasado colonial y frente a la potencia vecina, que no logró atraer al ranchero, ni al minero, ni al artesano por la insistencia de los líderes intelectuales liberales como Zavala, Mora, Ocampo y Lerdo de Tejada, de adoptar la teoría de la división de poderes y la economía individualista del laissez-faire, llevó al fracaso el proyecto modernizador liberal. ${ }^{13}$ La paz y la democracia imaginadas por los liberales triunfantes no fue el horizonte que siguió a la guerra civil. El escenario más bien de mayor discordia, llevó a Porfirio Díaz a emprender la revuelta de La Noria y, en vísperas de la reelección de Lerdo, logró instalarse en el poder tras la triunfante rebelión de Tuxtepec, en el cual permanecería hasta que una nueva revuelta lo sacara en 1910.

El matrimonio entre liberalismo y nacionalismo no fue la solución para nuestro desarrollo. No obstante haber imitado y adoptado las instituciones de Estados Unidos, la perversa historia nos tenía reservado el fracaso. ¿Y a quién culpar sino a Estados Unidos mismo? En lugar

${ }^{13}$ David Brading, op. cit., p. 138-9. 
de tomar en cuenta que la nación que emergió con el triunfo liberal fue una 'nación a la medida' de la minoría social que hizo suyo ese proyecto, se prefirió la sencillez de culpar al gran malvado.

Los liberales coincidieron con los conservadores: Estados Unidos era no sólo culpable del fracaso de Benito Juárez y de Sebastián Lerdo de Tejada por democratizar y poner en orden al país, sino del fracaso mismo del país por modernizarse. El mito del 'malvado' Estados Unidos se arraigó y alimentó justo cuando parecía que quienes estaban en el poder -quienes lo habían venerado y admirado- lo echarían por tierra.

A ello se sumó la visión que sobre México se tenía en Estados Unidos. El país era visto como un lugar de caos perpetuo; los mexicanos como seres inferiores. El fracaso por modernizarnos, el desorden que prevalecía al sur de la frontera del Imperio, fue la razón que mantuvo en el discurso anglosajón la intención de la anexión de mayor territorio mexicano a Estados Unidos. El 17 de julio de 1877, el diario estadounidense New York Herald publicó un mapa que incluía los estados mexicanos que, según el editor, Estados Unidos debía no sólo ocupar, sino anexarse, para lograr mayor orden y estabilidad en la región: Baja California, Sonora, Chihuahua, parte de Nuevo León, Sinaloa y Durango. ${ }^{14}$ Los motivos para seguir interviniendo en México no eran ya la expansión territorial que permitía a los Estados del Sur mantener la esclavitud. La Guerra Civil del vecino había concluido y con ello su ansia por expandirse. Ahora lo que se quería era el orden. Para México, Estados Unidos siguió representando la amenaza a temer. Por ello, la dictadura de Porfirio Díaz buscó contener la influencia del 'Coloso del Norte' enfocándose en la diversificación de las relaciones económicas mediante la búsqueda de capitales europeos.

No obstante la estabilidad económica y la modernización del país que produjo el porfiriato, la anhelada democracia seguía durmiendo el

${ }^{14}$ Lorenzo Meyer, "Focusing on Differences: The Historical Structure of US-Mexican Relations", en Transformations of Mexico and US-Mexico Relations, 2004, Washington, DC, Aspen Institute, p. 9. 
sueño de los justos. Teníamos una constitución vigente, la enarbolada por los liberales en 1857, que nos hacía una república representativa, democrática y federal, pero sólo en la letra. En los hechos seguíamos siendo el país sometido al yugo de la mano fuerte del dictador. La revuelta y el desorden se impusieron de nuevo. También el discurso del nacionalismo entró para ocupar un espacio primordial.

Con la Revolución mexicana, la identidad nacional era una vez más, y de manera estruendosa, dependiente de la independencia que se lograba frente al poderoso vecino. Las voces que temían a ese gigante al norte y que abogaban por la precaución abundaban:

La República de Estados Unidos nunca ha podido, ni podrá, ser leal y desinteresadamente una nación amiga de México; la Historia y la Geografía se encargan de demostrar esta aseveración, suministrando, a la vez, enseñanzas que debemos aprovechar para conservar y aún, acaso, hasta para garantizar nuestra integridad política y nuestra soberanía económica, contribuyendo, al mismo tiempo, a evitar que se lesionen los intereses de una raza, en cuya defensa representa México el papel de una extrema vanguardia [...] el poderosos ha abusado de su condición en tanto que el débil no procura por medios adecuados contrarrestar esa superioridad. ${ }^{15}$

Esta defensa de la soberanía, hecha por un ciudadano común, no podía ser ignorada por ningún político mexicano de la época. Todo lo contrario. A partir de la Revolución mexicana, el nacionalismo se ha impuesto sobre el patriotismo y ha seguido históricamente razones y objetivos políticos en donde el anti-americanismo ha resultado ser una herramienta útil que, aun cuando puede provenir de sentimientos y convicciones auténticas, también ha sido aprovechada por las élites gobernantes como recurso para avanzar en sus carrera profesionales, en sus intereses personales. ${ }^{16}$

15 Enrique E. Schulz, El Porvenir de México y sus relaciones con Estados Unidos, 1914, México, Tipografía Económica. Colección Benson de América Latina, Biblioteca de la Universidad de Texas en Austin.

${ }^{16}$ Alan Knight, US Mexican Relations 1910-1940, op. cit., p. 34. 
Así, cualquier acercamiento con la potencia se utilizaba en el discurso como una alianza con el mismísimo demonio, como una afrenta al nacionalismo, como la mayor de las traiciones. Ahí está la acusación de la 'alianza traicionera' con 'los gringos', que le hizo Huerta a Carranza cuando Estados Unidos decidió reconocer al gobierno del segundo (1913). La acusación fue hecha no con la intención última de controlar a los anglosajones intervencionistas (recordemos que Huerta, antes de que Estados Unidos le diera la espalda, era bastante complaciente con sus demandas e intereses y había logrado llegar, por unos instantes, a la presidencia del país con la ayuda del entonces embajador de Estados Unidos en México, Henry Lane Wilson) ${ }^{17}$ sino como forma de buscar apoyos para hacerse del poder.

La intervención estadounidense en 1914, la ocupación de tropas estadounidenses del puerto de Veracruz y la expedición punitiva de Pershing en 1916, no hicieron mas que exacerbar, con mucha razón, el recelo y el rencor hacia el vecino. Y del otro lado, prevalecía la visión que se tenía de México, la del eterno país de conflictos y subdesarro1lo. Una carta del poderoso magnate de los medios de comunicación estadounidenses, William Randolph Hearst, publicada en el Brooklyn Eagle, notaba la postura intervencionista que subsistía en el país vecino: "Las condiciones existentes en México por los últimos cuatro años no han sido de paz, si no de guerra, y peor aún. La intervención que pido de México no es con el propósito de hacer la guerra. Es con el propósito de terminar con ella. Nuestra indiferencia con las terribles condiciones que prevalecen en México no ha acabado con ellas. Las ha agravado." $" 18$

No es de sorprender la importancia que en esos años tomó la defensa de la autodeterminación y el interés nacional en la relación México-Estados Unidos. El mito se alimentaba y se arraigaba cultu-

${ }^{17}$ Al respecto, v. Alan Knight, Mexican Revolution, 1986, New York, Cambridge University Press, vol. 2, p. 68.

${ }^{18}$ William Randolph Hearst, "Intervene in Mexico, not to make but to end war, urges Mr. Hearst”, Brooklyn Eagle, julio 6, 1916. Colección Benson de América Latina, Biblioteca de la Universidad de Texas en Austin. 
ralmente. En el nacionalismo político que venía desde el siglo XIX, la defensa de la soberanía nacional era una parte medular y dependía de las crisis en las relaciones entre México y Estados Unidos: de la intervención, la invasión y los reconocimientos diplomáticos estadounidenses. ${ }^{19}$

\section{El pequeño Alamán dentro de todos}

El nacionalismo volvió a contraer nupcias, ahora con los que emergieron como la clase gobernante de la Revolución mexicana. El nacionalismo revolucionario encumbró como su principal destinatario a Estados Unidos. Las principales instituciones que se crearon tras una década de revuelta interna tuvieron en mente al imperio del norte: El himno nacional, cantado por primera vez en 1854: "mas si osare un extraño enemigo/profanar con sus plantas tu suelo/ piensa ¡Oh Patria querida! que el cielo/ un soldado en cada hijo te dio", se refería al Coloso del Norte. ${ }^{20}$ La Constitución de 1917 se concibió con la dedicatoria de controlar los intereses económicos, con fines políticos, del vecino en México y de evitar la intervención de la gran potencia en nuestros asuntos, cualesquiera que fueran.

La otra gran institución nacional, la Iglesia, también se vio envuelta en la dinámica de la relación bilateral. Miguel Palomar y Vizcarra, el primer vicepresidente de la Liga Nacional para la Defensa de la Religión, no encontraba, a finales de los años 20 del siglo XX, otro a quien atacar que a Estados Unidos en su defensa de la religión:

${ }^{19}$ Viroli anota que la historia muestra que cuando una nación se enfrenta a una crisis política o moral, el lenguaje del patriotismo o el del nacionalismo llegan a ganar homogeneidad intelectual ya que poseen una fuerza mobilizadora y unificadora que otros lenguajes carecen (p. 14). En el caso de México es claro que, como método de defensa y de supervivencia, en momentos de crisis, el lenguaje que ha prevalecido es el del nacionalismo sobre el del patriotismo.

${ }^{20}$ Enrique Krauze, "You and Us", en Andrew Selee, ed. Perceptions and Misconceptions in US Mexico Relations, 2005, Washington, DC, Woodrow Wilson International Center for Scolars, p. 10. 
Para nosotros y para todos los mexicanos que aspiramos a salvar a la patria, el imperialismo yankee representa la maldad intrínseca, y como tal, debe de ser resistido enérgicamente. La historia muestra que la mayoría de las desgracias nacionales que nos han acechado, se han debido al imperialismo norteamericano. ${ }^{21}$

El siglo XIX vio prosperar un nacionalismo político que se basaba en la exaltación de las raíces pre-coloniales y en la 'gringofobia'. Esta resistencia opuesta por Lucas Alamán a la cultura norteamericana ejerció posteriormente una influencia perdurable. Primero, el matrimonio entre liberalismo y nacionalismo mantuvo a la postre la imagen de Estados Unidos como el malvado, el vecino a temer. Después, permaneció y se alimentó por medio del nacionalismo revolucionario de donde emergieron las instituciones que funcionarían en el México del siglo XX.

México vivió así, casi desde el inicio de su independencia, con un nacionalismo político que colocaba la identidad nacional y el recelo al vecino en primerísimo lugar. El nacionalismo, como lo describe Alan Knight, asemejaba una bruma presente a lo largo del espectro político, la izquierda y la derecha, entre revolucionarios y conservadores, liberales y católicos. Más espeso en algunas regiones y más pronunciado en momentos específicos de crisis (1914), generado y alimentado por un proceso de aculturación que iba desde la educación formal, la tradición oral y hasta la experiencia histórica colectiva. ${ }^{22}$

Parafraseando el clásico dicho sobre el PRI, entrando al siglo $\mathrm{XX}$, todos los mexicanos llevaban a un pequeño Alamán dentro: una pequeña parte de los 'auténticos mexicanos' estaban forzosamente conformados por desprecio, resistencia y recelo a los norteamericanos. El mito era una realidad que se confirmaba a diario, tanto en la política nacional como en la política exterior.

${ }^{21}$ Jean Meyer, La Cristiada, vol. 1, p. 65-6, citado por Alan Knight, US-Mexican Relations (1910-1940), p. 44-5.

${ }^{22}$ Knight, p. 49. 


\section{El encuentro de las divergencias: nacionalismo político, no económico}

José Vasconcelos, al plasmar en La raza cósmica (1925) su tesis sobre la supremacía de la identidad latina-de México en particular-sobre su vecino del Norte, siempre la vara sobre la cual nos medimos, permitió seguir alimentando el mito. Vasconcelos, el 'Maestro de la Juventud de América', nada menos que desde la Secretaría de Educación Pública, argumentó que la pluralidad étnica y cultural de América Latina era el factor de enriquecimiento frente a la unidad de la población norteamericana: los sajones monolíticos frente a la pluralidad latina. La raza cósmica no es otra que la raza dotada de todas las potencialidades: material, intelectual y estética, de las cuatro grandes razas: la blanca, la roja, la negra y la amarilla.

En un principio, la meta de ver materializada esta superioridad encaminó al país a la búsqueda del desarrollo con un nuevo enfoque, totalmente interno. El nacionalismo y la soberanía se midieron, desde el inicio de la institucionalización del país en los años treinta del siglo veinte, con el enfoque de la autodeterminación política y, ahora también, económica. Nada, ni siquiera la especulación de intromisión estadounidense, era tolerada. El decoro del país estaba de por medio. México se veía más firme y más digno en tanto mejor se lograba contener la intervención de Estados Unidos en nuestros asuntos. Como muestra, la indignación del Presidente Abelardo Rodríguez ante la especulación de que su gobierno negociaba la cesión de mayor territorio a Estados Unidos (El Chamizal), cuestión que ocupó un espacio importante en los años que estuvo al frente del país (1932-34): “Mi gobierno no ha entrado en ningún acuerdo que implique la pérdida o modificación del territorio nacional o que dañe la dignidad del país, porque ni mis antecedentes como revolucionario o como mexicano, ni mi investidura de Jefe de la nación, permite siquiera dichas suposiciones. ${ }^{23}$ El discurso que enraizaba el mito seguía fortaleciéndose.

23 “La firmeza y dignidad de nuestra política exterior", El Universal, octubre 24, 1932. 
En lo internacional, aun cuando México fue reconocido formalmente como un actor a partir de nuestra entrada a la Liga de las Naciones en 1934, la actitud escéptica hacia el mundo prevaleció y fue la base que mantuvo en pie la autosuficiencia que nuestro nacionalismo exigía. La democracia ficticia, por usar el término de François Xavier Guerra, era tolerada porque el gobierno logró una forma de organización nacional incluyente en la política, con instituciones que conciliaban leyes y aspiraciones democráticas, que en la praxis eran diluidas con elecciones no-competitivas que intentaban canalizar el conflicto político y aseguraban la estabilidad y el crecimiento económico con un enfoque totalmente interno. Vendrá entonces el modelo aislacionista de 'sustitución de importaciones'.

México, al parecer, dejaba de ser el vecino desordenado y poco desarrollado. Pasamos de ser un país rural a uno urbano: en 1910 la población urbana era del 13 por ciento; para 1970, conformaba el 45 por ciento. El producto nacional bruto creció en un 74 por ciento entre 1950 y 1962 gracias al progreso de la industrialización que para 1962 era diez veces mayor que en 1910, y el ingreso real por habitante se elevó 188 por ciento de los años treinta a $1962 .{ }^{24}$

El pragmatismo de ver al país desarrollarse, convertirse finalmente en un actor moderno, urbano e industrial, permitió al Estado la holgura para ser un actor autoritario y centralista que envolvía a la población en la bandera nacional: el manto protector de México frente al mundo exterior. Dicho pragmatismo funcionó también con nuestro vecino. A lo largo de estos años la actitud de Estados Unidos hacia este nacionalismo mexicano se vio, sí, como un dolor de cabeza, pero también como un factor que lograba estabilizar al régimen mexicano y que servía como barrera frente a influencias externas, como la tentativa de alinearnos con los alemanes, con quienes simpatizaba gran parte de la clase media mexicana, durante la Segunda guerra mundial, o

\footnotetext{
${ }^{24}$ Presidencia de la República, 50 años de Revolución Mexicana en cifras, 1963, México, Nacional Financiera, p. 24, 31 y 39.
} 
frente al comunismo, más adelante. ${ }^{25}$ Son los años de la diplomacia del 'Buen Vecino', con Dwight D. Morrow y Josephus Daniels como embajadores en México en los que, por unos instantes, los rencores, recelos y resentimientos fueron menores, incluso en el marco de la expropiación petrolera de 1938.

A principios de los años setenta, una vez que el modelo de crecimiento y desarrollo basado en lo interno comenzó a dar señales claras de agotamiento, el nacionalismo económico y político se encontraron en una situación ambigua. Quizá fue el incentivo de lograr la supremacía vasconceliana, que ya se vislumbraba en el horizonte pero que una vez más parecía querer escapársenos, la que justificó la divergencia de caminos que emprendieron la realidad y el discurso nacionalista que tomó el país: hacia un lado miraron los negocios, la tecnología, el consumo, los medios masivos, la educación de las élites y la migración de los trabajadores: Estados Unidos era el vecino que representaba las oportunidades; hacia el otro lado se orientó el discurso político, el orgullo nacional e intelectual que permearon la opinión pública en los sentimientos de recelo y odio a todo lo que fuera anglosajón.

La divergencia se hizo evidente; hubieron sentimientos de nacionalismo para lo político y de patriotismo para lo económico. Ambos tenían dinámicas e intereses distintos. Lo que en lo político, cualquier intervención política directa, generaba de inmediato reacción y resentimiento, en lo económico, la entrada de inversiones estadounidenses por sí solas, no generaban la misma oleada de atención.

Daniel Cosío Villegas escribió mucho sobre las relaciones MéxicoEstados Unidos. En sus textos describe a México como un milagro histórico de supervivencia, frente a un Estados Unidos que es milagro de fecundidad; nosotros promesa; Estados Unidos realidad. ${ }^{26}$ La diferencia entre el discurso político defensivo frente a la potencia vecina y la realidad que nos obligaba a acercarnos de manera titubeante en

${ }^{25}$ Lorenzo Meyer y Josefina Vázquez, México frente a Estados Unidos, p. 206, citado en Knight, p. 52.

${ }^{26}$ Daniel Cosío Villegas, Problemas de América, 1997, México, Clío, p. 99. 
lo económico, era la forma en que México buscaba lograr esta fecundidad, tanto política como económica, que el vecino imperial obtuvo desde un siglo atrás, y aun antes.

También durante la Segunda guerra mundial y, sobre todo en la posguerra, la divergencia entre el discurso político que seguía firme, aclamando la primicia de la soberanía como forma de enarbolar el nacionalismo mexicano, y la lógica económica, que permitía buscar en el enemigo norteamericano las oportunidades del desarrollo, continuaron por caminos divergentes, sin mayores aspavientos. Esquizofrenia pura, sin síntomas alarmantes.

No fue sino hasta la búsqueda de un acercamiento más formal mediante la negociación bilateral del Tratado de Libre Comercio de América (TLCAN) en los noventa del siglo XX, cuando ambas realidades, ambos discursos, se vieron frente a frente. El tema de un nuevo acercamiento a los Estados Unidos exacerbó las diferencias políticas, lo cual no es de sorprender si tomamos en cuenta que la decisión del gobierno mexicano por negociar el TLCAN con Estados Unidos marcó un profundo cambio en la historia de las relaciones entre ambos países. Además de reconocer lo inevitable de la geografía, representó

96 la decisión consciente de romper con la visión que se enfocaba en nuestras diferencias culturales, ideológicas, religiosas, de idioma, que constituían, según el discurso, un obstáculo irreconciliable e irremontable. ${ }^{27}$ Estábamos frente a las puertas de la modernidad, pero la llave de entrada implicaba pactar con quien históricamente habíamos visto como el demonio encarnado. Teníamos que optar por continuar con el mito de la integración como sacrificio de nuestra identidad nacional, o decirle adiós al mito y ver hacia delante. Todo un reto cultural.

Las reacciones fueron diversas. Algunos aplaudieron los beneficios económicos por venir dada la apertura al próspero mercado de Norteamérica; otros protestaron por los costos políticos de este acercamiento; y un tercer grupo, claro está, sacó a relucir el temor por la

${ }^{27}$ Soledad Loaeza, op. cit., p. 155. 
influencia de lazos más cercanos con Estados Unidos y su efecto en la cultura mexicana. ${ }^{28}$

Las preguntas que se hacían algunos en México eran: ¿Qué ocurrirá? ¿Qué sobrará de México al concluirse esta última etapa de machacamiento? ¿Podrá resistir y, en ese caso, cuáles serán sus principales elementos de defensa? ¿Es tan avasalladora, como parece, la influencia norteamericana? A esas interrogantes habría que sumar otra: ¿Valía la pena, para el país y su viabilidad futura, seguir alimentando el mito de la maldad del vecino del norte? La respuesta fue la aceptación a un mayor acercamiento... pero una vez más, limitado a lo económico. El discurso político nacionalista permaneció... y con ello se daba mayor abono al terreno del mito.

\section{La otra mitad de la historia}

Hasta ahora, el enfoque del presente ensayo ha girado en torno al fracaso por lograr el desarrollo y la prosperidad anhelada dada nuestra vecindad con Estados Unidos. Algo que se suele olvidar, sobre todo por los más fervientes anti-yankees, es tomar en cuenta los beneficios que ya hemos recabado gracias a nuestra posición geográfica y la serie de factores exclusivamente internos, de los cuales los responsables somos únicamente los mexicanos y que también juegan un papel importante en la historia de nuestro subdesarrollo.

En un enfoque exclusivo de los años recientes, la vecindad con Estados Unidos ha significado oportunidades económicas, con efectos políticos, sumamente favorables. En el plano económico, somos el tercer socio comercial del mayor consumidor del mundo. El Tratado de Libre Comercio ha traído consigo un aumento sin precedentes en inversión y comercio. En el 2005, México exportó mercancías por 170 mil 200 millones de dólares a EU. ${ }^{29}$ La inversión de la potencia vecina

${ }^{28}$ Ibid., p. 146.

${ }^{29}$ Oficina de Información sobre Economía, Comercio e Industria de Estados Unidos. 
ha sido creciente, llegando en su punto más alto en el 2001, a los 15 mil millones de dólares. ${ }^{30}$

En el plano político, el TLCAN ha funcionado como un espejo, el cual nos ha obligado a vernos como somos y adentrarnos en el debate de qué país queremos. Varios son los estudios serios que colocan al TLCAN, la asociación económica con Estados Unidos, como uno de los catalizadores del cambio democrático en México; como la perestroika que permitió que se llevara a cabo el glasnost mexicano.

¿Y cómo dejar de lado la válvula de escape que la migración de mexicanos a Estados Unidos ha representado para el país? Las remesas y la oportunidad de empleo y de un futuro mejor en Estados Unidos han sido un sustento para millones de nuestros nacionales. Para ellos, así como para muchos empresarios, artistas o académicos, la cercanía con Estados Unidos ha significado beneficios económicos que hacen de la frontera un lugar de oportunidades y no la antesala del infierno; oportunidades que, por cierto, en México les son negadas.

Además de lo anterior, es importante tomar en cuenta las razones exclusivamente internas que son causa importante de nuestro subdesarrollo. Líneas arriba se habla de la democracia ficticia. ¿Qué papel le damos al hecho de que, durante décadas y en el nombre de la estabilidad económica y política, nos rigiéramos por un sistema político autoritario, demagógico y corrupto? También se hace mención de nuestra economía cerrada. ¿Cuál es la consecuencia para nuestro desarrollo de empeñarnos en llegar tarde a las citas con la modernización? Hoy seguimos montados sobre la idea de que abrir la industria energética a la modernización es una manera de entregar nuestra soberanía nacional en las garras del ogro extranjero. ¿Cuánto nos cuesta este empeño por conservar el status quo? Es preciso, para entender nuestro pasado y para decidir sobre qué camino seguir en el futuro, tomar en cuenta la historia completa: la vecindad con Estados Unidos ha implicado costos que otorgan fundamentos claros para la desconfianza, el temor y el resentimiento, pero también beneficios que nos obligan a hacer

\footnotetext{
${ }^{30}$ Departamento de Comercio de EU.
} 
un balance sobre qué tanto de nuestro nacionalismo ha impedido una mayor prosperidad para el país.

\section{De ida y de vuelta: el miedo a la integración}

México ha sido el México del patriotismo criollo, el liberal, la nación conservadora, la República posible, la gran familia revolucionaria y ahora, el país democrático. En todas estas etapas, el otro ha sido un factor importante, determinante. La presencia de Estados Unidos, "aquel fantasma de carne y hueso que los liberales no supieron combatir, y que el porfiriato apaciguó en el campo abierto de la inversión extranjera, pero con el que siguió peleando en la sombra", ${ }^{31}$ aquella presencia que con la magia de su reconocimiento o rechazo diplomático fue testigo activo de la Revolución y de su larga institucionalización, y que ahora, como desde hace más de una década, es el socio que en el campo económico pone en evidencia el doble discurso y toca las fibras sensibles de la gran amenaza: la amenaza a nuestra identidad - el gran mito de las relaciones México-Estados Unidos- y la esperanza del desarrollo.

Cuestionarnos si integrarnos a Estados Unidos implica dejar de ser 'auténticamente mexicanos' resulta ocioso, por tardío y alarmista: el proceso de integración, tanto económico como político, lleva mucho tiempo dándose y la expectativa a futuro es que sea un proceso que se siga intensificando. Con 12 millones de mexicanos radicados al otro lado, no podría ser de otra manera. La influencia norteamericana se deja sentir hoy, como desde siempre, en muchos terrenos; en los hábitos de alimentación y el vestido; en el lenguaje, en el pensamiento, en los ideales de vida; en la economía, en la sociedad, en las artes y en la educación. La influencia norteamericana sobre México es ya, como diría Cosío Villegas, como el Dios de los cristianos: omnipotente y omnipresente. ${ }^{32}$ Lo anterior no significa que seamos menos mexicanos,

\footnotetext{
${ }^{31}$ Héctor Aguilar Camín, op. cit., p. 57.

${ }^{32}$ Daniel Cosío y Villegas, p. 98.
} 
si no que, como mexicanos, tenemos una historia y una cultura llena de influencias norteamericanas. Y de muchas otras. Nuestra cultura, lo ha dicho Héctor Aguilar Camín, es la 'celebración de la diversidad' y no es estática: evoluciona, se mueve, marcha.

Por ello, la integración como sacrificio de nuestra identidad nacional es un mito. Y lo más interesante es que el mito va en ambos sentidos. Mientras los mexicanos dilucidamos si queremos o no ser parte de Norteamérica por el miedo a las consecuencias de esta integración que queramos o no ya se está dando, hoy en Estados Unidos también están presentes y se escuchan las voces que ven en esta integración la principal amenaza a la 'unión' de Estados Unidos.

Ahí está Samuel Huntington y su pregunta: ¿Quiénes somos? (Who are we?), libro en el cual el politólogo estadounidense plasma a los inmigrantes en general y a los mexicanos en particular como EL GRAN RETO para el futuro de su país dada una serie de factores, entre ellas la cercanía geográfica a sus raíces y la fortaleza de éstas. Paradoja de paradojas: creíamos que nuestra identidad se perdería, pero los nuestros en Estados Unidos provocan, con la fuerza de sus tradiciones, el temor de que los mecanismos norteamericanos de integración fallen

100 y el país vecino pierda su identidad. Ahora resulta que los que tienen problemas de identidad son ellos; 'el otro'.

De acuerdo con Huntington, la gran diferencia entre la cultura mexicana y la anglosajona en cuanto a religión, valores e idioma, no permite a estos emigrantes asimilarse a la sociedad estadounidense como sí lo hicieron otros grupos que también se han establecido en el país vecino, como los alemanes o polacos a principios del siglo XX. Por ello, estos emigrantes mexicanos representan un reto para la identidad estadounidense. Una década antes que él, el historiador Arthur Schlesinger ya alertaba sobre los peligros de la inmigración en The Disuniting of America. ${ }^{33}$

33 Arthur Schlesinger, The Disuniting of America, 1992, New York, W.W. Norton \& Company. 
Resulta fascinante mirar atrás y leer sobre el miedo de los mexicanos a ser succionados por la avasalladora cultura norteamericana, y encontrarnos hoy con un libro como el de Huntington que habla exactamente de este mismo miedo, pero visto desde el otro lado de la frontera. La noción del otro se ha desdibujado. La identidad nacional de ambos está marcada por una historia común de convivencia y la integración con Estados Unidos, lejos de significar la disolución de nuestra identidad nacional, es más bien una palanca de transformación y enriquecimiento.

\section{¿Adiós al mito?}

La identidad nacional no es un tesoro fijo que hay que resguardar en una vitrina para evitar su contaminación por el contacto con el exterior, algo que debemos guardar y proteger celosamente del otro. Es más bien parte de la marea en el océano, algo que está en movimiento, que se ve alimentado y retroalimentado por este constante ir y venir, por el contacto de los otros con nosotros y que enriquece a los otros por su contacto con nosotros. Está aquí, en casa, el seguir abonando el terreno de los mitos, del otro como ogro malvado, y dejar que la integración ocurra de manera inercial, o asumir que la mundialización nos lleva, inevitablemente, a la integración.

Tanto mexicanos como estadounidenses nos debatimos en cómo asumir nuestra vecindad. Hoy en México la pregunta viva es si queremos o no asumirnos como parte de Norteamérica. Seguimos, como diría Edmundo O' Gorman, buscando hacernos de la prosperidad de Estados Unidos, pero sin querer renunciar al modo de ser tradicional por pretender aferrarnos así a una idea de lo que es nuestra nación. Queremos los beneficios de la modernidad, pero no la modernidad misma. Hay datos contundentes e irrebatibles: la vecindad geográfica, los intereses en común que ello genera y la integración que ya se está dando. Hay otros que son mitos que han estado presentes a lo largo de nuestra historia común: nosotros los débiles, las víctimas; el otro, 
el ogro devorador, el vecino en quien desconfiar, el rival imperial. Está en nosotros decidir: ¿qué queremos destacar en nuestra relación con Estados Unidos, los hechos actuales y las posibilidades futuras o los mitos? ¿Queremos seguir alimentando una historia de recelos y rencores que quizás en el pasado tuvieron sustento, pero que hoy es más bien un antifaz que no nos permite ver las muchas oportunidades que la vecindad con Estados Unidos representa? ¿Queremos dejar de alimentar y desterrar de una vez por todas el mito? ¿Queremos o no decirle adiós?

Las consecuencias de continuar alimentando los mitos son fáciles de predecir: más de lo mismo; más de la relación de recelos, miedos, frustraciones y de defensa a ultranza del 'nosotros'. Más parroquialismo. Más localismo. Más ensimismamiento. De Norteamérica, ni hablemos. Dejemos las cosas a la inercia; continuemos con el discurso de buenos y malos, verdugos y víctimas. Continuemos sufriendo nuestra geografía. Por otro lado, son difíciles de predecir los alcances de desterrar el mito, de cambiar la tradición empezando por el discurso político y la constante negativa por observar los dos lados de la moneda (lo interno y lo externo) al momento de revisar nuestros fracasos y

102 limitaciones, factores que permiten que el mito se arraigue en nuestra cultura y no asumir los hechos. En toda una historia en común no nos hemos aventurado por este camino. 